\title{
Intramedullary schwannoma of conus medullaris: rare site for a common tumor with review of literature
}

\author{
Ritika Singh $^{1} \cdot$ Sujata Chaturvedi ${ }^{1} \cdot$ Ishita Pant $^{1} \cdot$ Gurbachan Singh $^{2} \cdot$ Rima Kumari $^{3}$
}

Received: 24 July 2018 / Revised: 16 October 2018 / Accepted: 22 October 2018

(c) International Spinal Cord Society 2018

\begin{abstract}
Introduction Schwannomas at an intramedullary location constitute only $0.3 \%$ of primary spinal tumors. Those in the conus are extremely rare, especially in the absence of neurofibromatosis, with only 12 cases reported in the literature so far, excluding the present case.

Case presentation We report the case of a 27-year-old female who presented with complaints of backache since 1 year, weakness in both lower limbs with tingling and numbness since 6 months, and urinary incontinence since 1 month. There was no history of trauma or any skin lesions. Magnetic resonance imaging (MRI) of the spine provided a provisional diagnosis of ependymoma. The patient was operated upon, histopathology revealed it to be a schwannoma.

Discussion Intramedullary schwannomas without neurofibromatosis are extremely rare at the conus and can be completely resected unless there is infiltration. Gliomas and ependymomas are commoner entities at this site, which are usually subtotally resected. This case highlights that although extremely rare, the possibility of a schwannoma may be considered in the differentials of an intramedullary spinal lesion.
\end{abstract}

\section{Introduction}

Spinal schwannomas comprise a third of all intraspinal neoplasms [1] and commonly occur in association with neurofibromatosis. Intramedullary schwannomas, in contrast, constitute $1.1 \%$ of all spinal schwannomas and only $0.3 \%$ of all intramedullary tumors [2]. Most commonly, intramedullary schwannomas arise in cervical and thoracic spine [2]. Those in the conus (in the absence of neurofibromatosis) are quite exceptional, and to the best of our knowledge, only 12 cases have been reported in the literature so far, excluding the present case. This case is being reported for its unusual location, and the clinico-

Sujata Chaturvedi

drsujatacv@gmail.com

1 Department of Pathology, Institute of Human Behaviour and Allied Sciences, Delhi, India

2 Department of Neurosurgery, Guru Teg Bahadur Hospital, Delhi, India

3 Department of Radiology, Institute of Human Behaviour and Allied Sciences, Delhi, India radiological features with pathological findings are discussed along with related literature review.

\section{Case presentation}

A 27-year-old patient presented with complaints of moderate intensity lower backache for 1 year, which was followed 6 months later by insidious onset weakness in both lower limbs with tingling and numbness, which caused recurrent falls. She also developed urinary incontinence 1 month before presentation. She had no history of spinal cord injury or previous back surgery. Neurological examination revealed normal bulk and tone of lower limb muscles, however motor strength was reduced in both lower limbs with bilateral power $3 / 5$. There was a diminished sensation for hot and cold temperature, touch and pain in both lower limbs.

Magnetic resonance imaging (MRI) of lumbosacral spine showed a T2W hyperintense solid cystic lesion in the conus medullaris involving the cauda equina roots. On contrast administration, cystic component showed peripheral enhancement and solid area showed nodular enhancement (Fig. 1a, b). A provisional diagnosis of an intramedullary spinal tumor was made, with ependymoma and astrocytoma as differentials. 
A T12-L1 laminectomy was performed and after dissecting dura and arachnoid, a soft to firm, grayish-white intramedullary tumor was seen. Subtotal resection of the mass was performed and perioperative diagnosis of ependymoma was made. Haematoxylin and Eosin (H\&E)
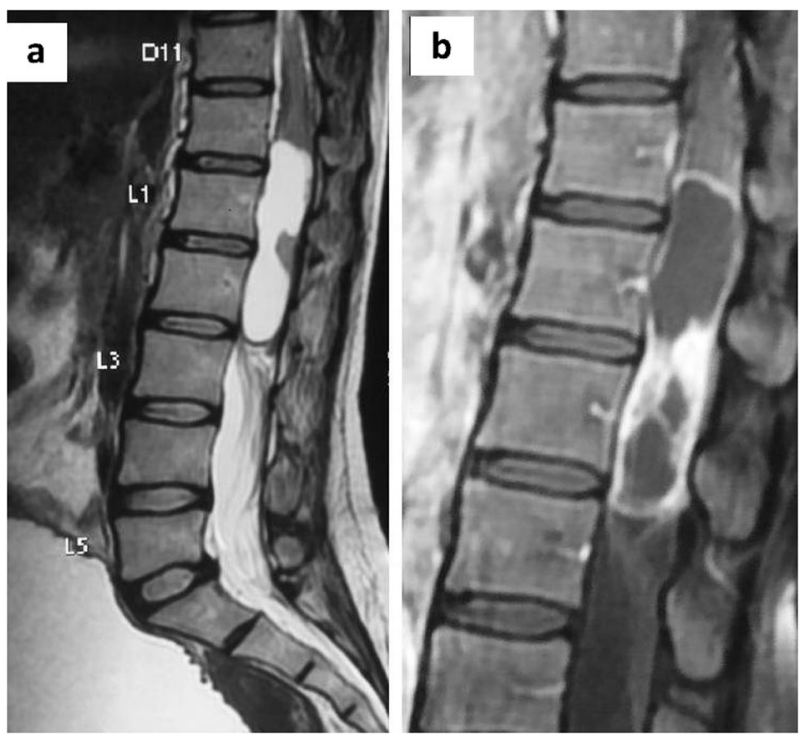

Fig. 1 a, b Sagittal T2W and T1 post-contrast images of lumbar spine reveal a complex mixed solid cystic intradural mass at L1-L2 level arising from the conus, compressing and displacing the cauda equina nerve roots, and showing heterogenous rim enhancement stained intra-operative smears were made and a diagnosis of a papillary tumor was made.

Routine histopathologic examination of paraffin sections on H\&E showed a biphasic tumor with predominantly hypocellular areas composed of loosely scattered cells in illdefined fascicles. The cells were small oval to spindleshaped with oval nuclei and bland chromatin. The hypercellular areas showed cells arranged in palisades and occasional Verocay bodies were seen (Fig. 2a, b). Tumor cells were immunopositive for S-100 and NFP; immunonegative for GFAP (Fig. 2c, d). Final histopathological diagnosis of a schwannoma was made. In light of this, the MRI scans and Squash smears were re-examined and a diagnosis of intramedullary schwannoma established.

Post-operative period was uneventful. Power in lower limbs improved to $4 / 5$. Presently, at 6 monthly follow up done a month back, the patient was walking with assistance.

\section{Discussion}

Schwannomas are slow growing, benign tumors of the peripheral nervous system originating from Schwann cells and usually located intradural, extramedullary, or extradurally [1].

Intramedullary schwannomas are rare tumors comprising just $0.3 \%$ of all intraspinal neoplasms and have a
Fig. 2 a Histopathology showing a biphasic tumor with predominantly hypocellular areas composed of loosely scattered cells in ill-defined fascicles. Cells were small oval to spindle-shaped with oval nuclei and bland chromatin. b Histopathology showing hypercellular areas, which comprise cells arranged in palisades and occasional Verocay bodies were seen. c, $\mathbf{d}$ Tumor cells were immunopositive for S-100 (c) and immunonegative for GFAP (d)
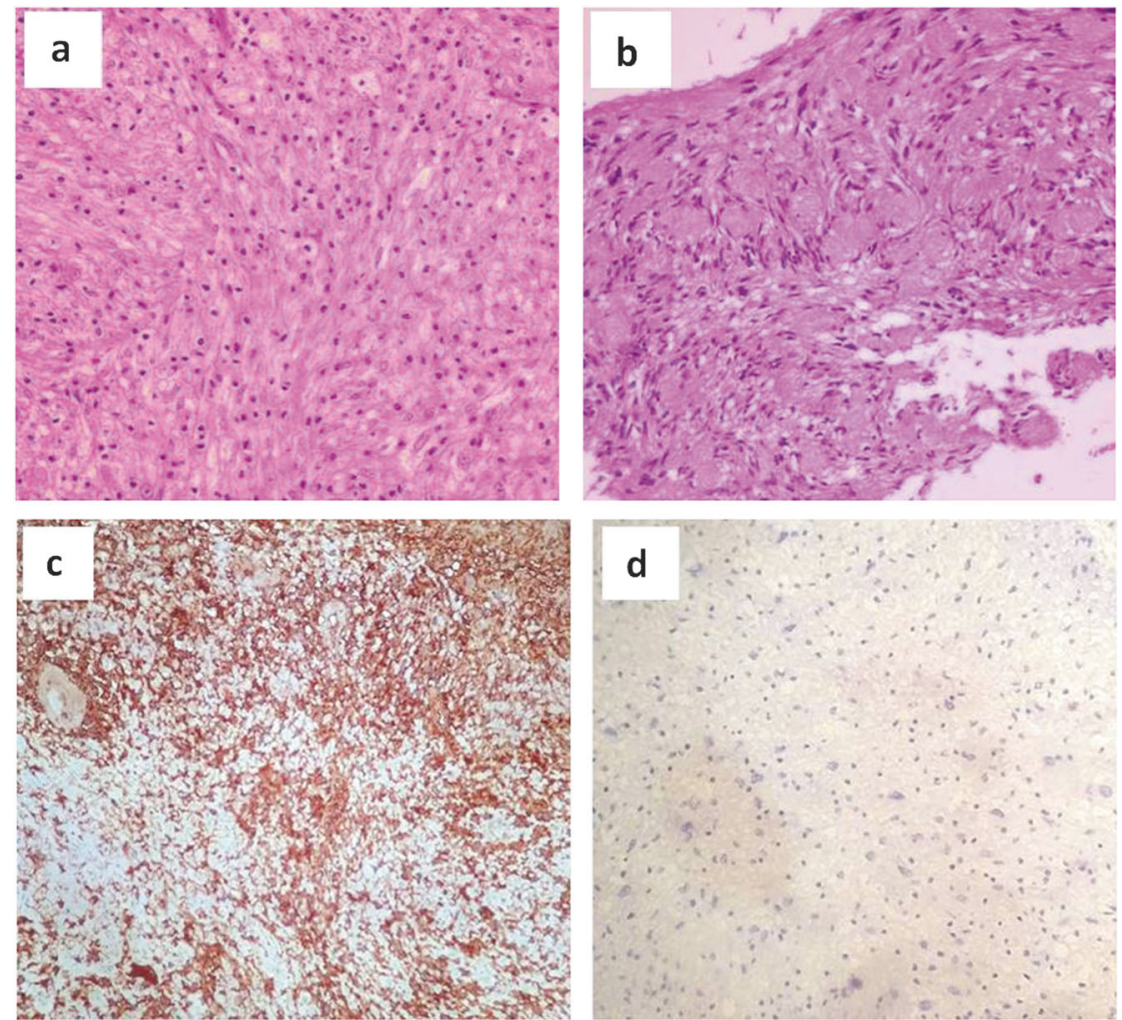


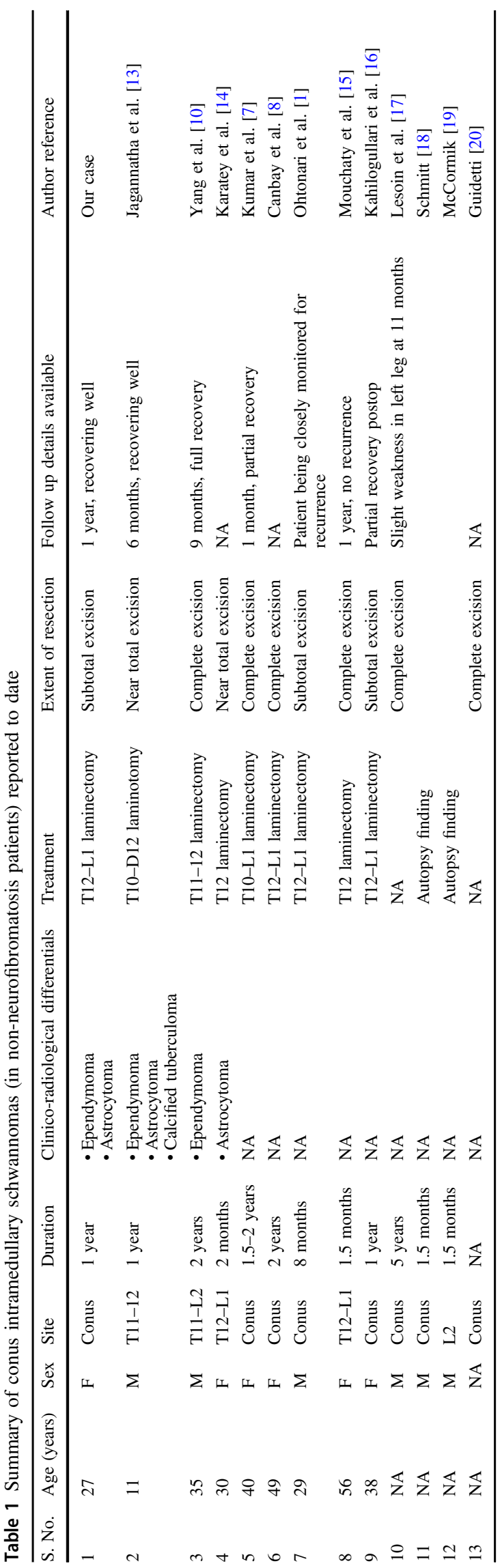

predilection to localize to cervical and thoracic spine. Till date, 12 cases (excluding present case) of intramedullary schwannoma of conus region without neurofibromatosis have been reported in the literature, with only 2 previous cases being reported from India (Table 1).

This rarity is due to the absence of Schwann cells in the central nervous system. Several theories have been put forward to explain this anomaly, including ectopic Schwann cells originating from embryonal neural tube, transformation of pial cells from neuroectoderm into Schwann cells, migration of Schwann cells into the cord in response to cord trauma, proliferation of Schwann cells in the nerve fibres of spinal arteries, and Schwann cells extending into cord from the region where spinal nerve roots enter pia mater [3-5].

These are generally slow-growing tumors manifesting in the fourth to fifth decade, with a predilection for men (M:F $=3: 1$ ). They rarely cause clinical symptoms at an earlier age and are usually diagnosed late [6]. The symptomatology of schwannomas includes neurological signs and symptoms and neurological deficits depending on tumor location. These present with pain, motor and sensory changes with sphincter disturbances [7].

Intramedullary schwannomas generally have no specific radiological features. The common differentials at this site are gliomas-ependymoma and astrocytoma, and MRI features overlap. These schwannomas generally have low to intermediate signal intensity on T1-weighted images. On T2-weighted images, they may be heterogeneous with focal areas of hyperintensity and hypointensity, hemorrhage, and collagen deposition [8]. A well-defined plane of cleavage, intense contrast enhancement, presence of an additional extramedullary component, and thickening of nerve roots are features characteristic but not diagnostic of a schwannoma. Therefore, a definite pre-operative diagnosis of an intramedullary schwannoma solely on MRI findings is difficult, as substantiated by Nicoletti et al. [9].

Surgery is the treatment of choice for intraspinal intramedullary schwannomas. As compared to gliomas, schwannomas usually have defined plane of cleavage and it is hence possible to perform a gross total excision $[8,10]$. In cases with nerve root involvement or dense adhesions to surrounding tissue, subtotal excision is advised to avoid unacceptable surgical complications [1]. Residual tumor can be removed later in a second operation as demonstrated successfully by Hida et al. [11]. Adjuvant treatment options like radiotherapy, chemotherapy have not shown good results in spinal intramedullary neoplasms. Newer therapeutic strategies including directed drug delivery and nanomedicine techniques are being investigated for these patients [12].

As in the present case, 4 recent cases listed in Table 1 were initially thought to be ependymomas/astrocytomas, suggesting a radio-pathological mismatch. The authors advocate performing an intra-op frozen section to narrow 
down differentials and decide the extent of surgical resection to be done.

\section{Conclusion}

Intramedullary schwannomas without neurofibromatosis are extremely rare at the conus and can be completely resected unless there is infiltration. Gliomas and ependymomas are commoner entities at this site, which are usually subtotally resected. This report highlights that despite the rarity, a schwannoma should be considered in the differentials of intramedullary spinal tumors, as complete resection can be done for these to achieve a cure.

\section{Compliance with ethical standards}

Conflict of interest The authors declare that they have no conflict of interest.

Informed consent Written informed consent was obtained from the patient for publication of this manuscript and any accompanying images.

\section{References}

1. Ohtonari T, Nishihara N, Ota T, Ota S, Koyama T. Intramedullary schwannoma of conus medullaris complicated by dense adhesion of neural tissue. Neural Medchir. 2009;49:536-8.

2. Binatli O, Ersahin Y, Korkmaz O, Bayol U. Intramedullary schwannoma of the spinal cord: a case report and review of the literature. J Neurosurg Sci. 1999;43:163-8.

3. Ramamurthi B, Anguli VC, Iyer CG. A case of intramedullary neurinoma. J Neurol Neurosurg Psychiatry. 1958;21:92-4.

4. O'Brien DF, Farrell M, Fraher JP, Bolger C. Schwann cell invasion of the conus medullaris: case report. Eur Spine J. 2003;12:328-31.

5. Russel D, Rubinstein LJ, editors. Pathology of tumors of the nervous system. 3rd ed. London: Edward Arnold; 1971.
6. Takemoto K, Matsumura Y, Hashimoto H, Inoue Y, Fukuda T, Shakudo M. et al. MR imaging of intraspinaltumors-capability in histological differentiation and compartmentalization of extramedullary tumors. Neuroradiology. 1988;30:303-9.

7. Kumar R, Mittal RS. Intramedullary schwannoma of conus medullaris: case report and review of the literature. World Spinal Column J. 2014;5:1-5.

8. Canbay S, Hasturk AE, Markoc F, Caglar S. Schwannoma of conus medullaris: a rare case. Chin J Cancer. 2011;30:867-70.

9. Nicoletti GF, Passanisi M, Castana L, Albanese V. Intramedullary spinal neurinoma: case report and review of 46 cases. J Neurosurg Sci. 1994;38:187-91.

10. Yang T, Wu L, Yang C, Deng X, Xu Y. Coexisting intramedullary schwannoma with an ependymal cyst of the conus medullaris: a case report. Oncol Lett. 2015;9:903-6.

11. Hida K, Yano S, Iwasaki Y. Staged operation for huge cervical intramedullary schwannoma: report of two cases. Neurosurgery. 2008;62:456-60.

12. Tobin MK, Geraghty JR, Engelhard HH, Linninger AA, Mehta AI. Intramedullary spinal cord tumors: a review of current and future treatment strategies. Neurosurg Focus. 2015;39:E14.

13. Jagannatha AT, Joshi KC, Rao S, Srikantha U, Varma RG, Mahadevan A. Paediatric calcified intramedullary schwannoma at conus: A common tumor in a vicarious location. J Pediatr Neurosci. 2016;11:319-21.

14. Karatay M, Koktekir E, Erdem Y, Celik H, Sertbas I, Bayar MA. Intramedullary schwannoma of conus medullaris with syringomyelia. Asian J Surg. 2017;40:240-2.

15. Mouchaty H, Conti R, Buccoliero AM, Conti P. Intramedullary melanotic schwannoma of the conus medullaris: a case report. Spinal Cord. 2008;46:703-6.

16. Kahilogullari G, Aydin Z, Ayten M, Attar A, Erdem A. Schwannoma of the conus medullaris. BJ ClinNeurosciences. 2005;1:80-1.

17. Lesoin F, Delandsheer E, Krivosic I, Clarisse J, Arnott G, Jomin M. Solitary intramedullary schwannomas. Surg Neurol. 1983;19:51-6.

18. Schmitt HP. "Epi-" and intramedullary neurilemmoma of the spinal cord with denervation atrophy in the relatedskeletal muscles. J Neurol. 1975;209:271-8.

19. McCormick WF. Intramedullary spinal cordschwannoma. A unique case. Arch Pathol. 1964;77:378-82.

20. Guidetti B. Intramedullary tumours of the spinal cord. Acta Neurochir (Wien). 1967;17:7-23. 